\title{
Erratum to: Creep Behavior of Bonded Anchor Under High Sustained Loading at Long Term Temperature
}

\author{
Giovanni Muciaccia ${ }^{(\bowtie)}$, Andrea Consiglio, and Gianpaolo Rosati \\ Department of Civil and Environmental Engineering, Politecnico di Milano, \\ Piazza Leonardo da Vinci, 32, 20133 Milan, Italy \\ \{giovanni. muciaccia, andreanino. consiglio, \\ gianpaolo.rosati\}@polimi.it
}

\section{Erratum to: \\ Chapter "Creep Behavior of Bonded Anchor Under High Sustained Loading at Long Term Temperature" in: D.A. Hordijk and M. Luković (eds.), High Tech Concrete: Where Technology and Engineering Meet, https://doi.org/10.1007/978-3-319-59471-2_111}

In the original version of the book, the deleted reference "Priyank, U., Kumar, S.: Pull-out capacity of adhesive anchors: an analytical solution. Int. J. Adhes. Adhes. 60, 54-62 (2015). https://doi.org/10.1016/j.ijadhadh.2015.03.006" has to be inserted again in the reference list of Chap. 111. The erratum chapter and the book have been updated with the change.

The updated online version of this chapter can be found at https://doi.org/10.1007/978-3-319-59471-2_111 